\title{
Stenotrophomonas koreensis sp. nov., isolated from compost in South Korea
}

\author{
Correspondence \\ Sung-Taik Lee \\ e_stlee@kaist.ac.kr
}

\author{
Hee-Chan Yang, Wan-Taek Im, Myung Suk Kang, Do-Yun Shint \\ and Sung-Taik Lee
}

Department of Biological Sciences, Korea Advanced Institute of Science and Technology, 373-1, Guseong-dong, Yuseong-gu, Daejeon 305-701, Republic of Korea

\begin{abstract}
A Gram-negative, rod-shaped, non-spore-forming bacterium (TR6-01 ${ }^{\top}$ ) was isolated from compost near Daejeon city in South Korea. On the basis of 16S rRNA gene sequence similarity, strain TR6-01 ${ }^{\top}$ was shown to belong to the class Gammaproteobacteria, related to Stenotrophomonas acidaminiphila (97.1\%) and Stenotrophomonas maltophilia (96.9\%); the phylogenetic distance from any other established species within the genus Stenotrophomonas was less than $97 \cdot 0 \%$. Phenotypic and chemotaxonomic data (major ubiquinone Q-8; fatty acid profile) supported the affiliation of strain TR6-01 ${ }^{\top}$ to the genus Stenotrophomonas. The results of DNA-DNA hybridization and physiological and biochemical tests allowed genotypic and phenotypic differentiation of strain TR6-01 ${ }^{\top}$ from the five Stenotrophomonas species with validly published names. TR6-01 ${ }^{\top}$ therefore represents a novel species, for which the name Stenotrophomonas koreensis sp. nov. is proposed, with the type strain TR6-01 ${ }^{\top}\left(=\mathrm{KCTC} 12211^{\top}=\mathrm{JCM} 13256^{\top}\right)$.
\end{abstract}

During a course of study on the culturable aerobic bacterial community in compost sampled near Daejeon city in Korea, a large number of novel bacterial strains were isolated (Im et al., 2003). One of these isolates (strain TR6-01 ${ }^{\mathrm{T}}$ ) was member of genus Stenotrophomonas in the class Gammaproteobacteria and was the subject of this taxonomic investigation.

The genus Stenotrophomonas was first described by Palleroni \& Bradbury (1993) and, at present, the genus comprises the five species Stenotrophomonas acidaminiphila Assih et al. 2002, S. africana Drancourt et al. 1997, S. maltophilia (Hugh 1981) Palleroni and Bradbury 1993, S. nitritireducens Finkmann et al. 2000 and S. rhizophila Wolf et al. 2002.

In the present study, we conducted a phylogenetic analysis on the basis of $16 \mathrm{~S}$ rRNA gene sequences, DNA-DNA hybridization tests and some important phenotypic characteristics to determine the precise taxonomic position of this strain. On the basis of the results obtained in this study, we propose that strain TR6- $01^{\mathrm{T}}$ should be placed in the genus Stenotrophomonas as the type strain of a novel species.

tPresent address: School of Civil, Urban and Geosystem Engineering, Seoul National University, Shillim-dong, Gwanak-gu, Seoul, Korea.

The GenBank/EMBL/DDBJ accession number for the $16 \mathrm{~S}$ rRNA gene sequence of strain TR6- $01^{\top}$ is $\mathrm{AB} 166885$.

The fatty acid profile of Stenotrophomonas koreensis compared with other Stenotrophomonas species is available as a supplementary table in IJSEM online.
Strain TR6- $01^{\mathrm{T}}$ was originally isolated from a compost which was composed of cow dung and rice straw, near Daejeon city in South Korea. This compost sample was suspended with $50 \mathrm{mM}$ phosphate buffer $(\mathrm{pH} \mathrm{7 \cdot 0)}$ and the suspension was spread on R2A agar plates (Difco) after serial dilution with $50 \mathrm{mM}$ phosphate buffer $(\mathrm{pH} \mathrm{7 \cdot 0)}$. The plates were incubated at $30^{\circ} \mathrm{C}$ for 2 weeks. Single colonies on the plates were purified by transferring them onto new plates and were incubated once again under the same conditions. The purified colonies were tentatively identified by partial sequences of the 16S rRNA gene (Im et al., 2003). TR6-01 ${ }^{\mathrm{T}}$ was one of the dominant isolates on the R2A agar plates under aerobic conditions. This organism was deposited in the Korean Collection for Type Cultures as KCTC $12211^{\mathrm{T}}$ $\left(=\mathrm{JCM} 13256^{\mathrm{T}}\right)$. Other type strains of species of the genus Stenotrophomonas were obtained from the DSMZ or KCTC.

The Gram reaction was performed by the non-staining method as described by Buck (1982). Cell morphology was observed under a Nikon light microscope at $\times 1000$, with cells grown for 2 days at $30^{\circ} \mathrm{C}$ on R2A agar. Catalase and oxidase tests were performed by the procedures outlined by Cappuccino \& Sherman (2002). Substrate utilization as sole carbon source and some physiological characteristics were determined with API 32GN and API 20NE galleries according to the instructions of the manufacturer (bioMérieux). Anaerobic growth was performed in serum bottles adding thioglycolate $\left(1 \mathrm{~g} \mathrm{l}^{-1}\right)$ to R2A broth and substituting the upper air layer with nitrogen gas. Nitrate and nitrite reduction were later confirmed by inoculating, in each case, into three serum bottles $(25 \mathrm{ml})$ containing $13 \mathrm{ml} \mathrm{R} 2 \mathrm{~A}$ media, 
while nitrate and nitrite were added as $\mathrm{KNO}_{3}$ and $\mathrm{NaNO}_{2}$ at concentrations of $10 \mathrm{mM}$. The reduction of nitrate and nitrite was monitored by ion chromatograph (model 790 personal IC; Metrohm) equipped with a conductivity detector and anion exchange column (Metrosep Anion Supp 4; Metrohm). Degradation of DNA [using DNA agar (Difco) supplemented with $0.01 \%$ toluidine blue (Merck)], degradation of casein, chitin, cellulose and starch (Atlas, 1993), degradation of lipids (Kouker \& Jaeger, 1987) and degradation of xylan (Ten et al., 2004) were also investigated; reactions were read after 5 days. Growth at different temperatures and $\mathrm{pH}$ was assessed after 5 days incubation. Salt tolerance was tested on R2A medium supplemented with $1-10 \%(w / v) ~ N a C l$ after 5 days incubation. Duplicate antibiotic-sensitivity tests were done using filter-paper discs containing the following: streptomycin $(5,10$ and $15 \mu \mathrm{g})$, tetracycline $(5,10$ and $15 \mu \mathrm{g})$, kanamycin $(1 \cdot 0,1 \cdot 5$ and $2.0 \mathrm{mg})$ and ampicillin (20,30 and $50 \mu \mathrm{g})$ (Sigma). Discs were placed on R2A plates spread with TR6- $01^{\mathrm{T}}$ culture and were then incubated at $30{ }^{\circ} \mathrm{C}$ for 5 days.

Extraction of genomic DNA, PCR-mediated amplification of the 16S rRNA gene and sequencing of purified PCR product were carried out according to Im et al. (2004). The $16 \mathrm{~S}$ rRNA gene sequences of related taxa were obtained from GenBank. The multiple alignments were performed by CLUSTAL_X program (Thompson et al., 1997). Gaps were edited using the BIOEDIT program (Hall, 1999). The evolutionary distances were calculated using the Kimura twoparameter model (Kimura, 1983). The phylogenetic tree was constructed by using the neighbour-joining method (Saitou \& Nei, 1987) using the MEGA2 program (Kumar et al., 2001) with bootstrap values based on 1000 replications (Felsenstein, 1985) (Fig. 1).

The G $+\mathrm{C}$ content of the chromosomal DNA was determined as described by Mesbah et al. (1989) using reversedphase HPLC. Quinones were extracted from cells grown on nutrient broth (Difco) and analysed as described by Komagata \& Suzuki (1987) using reversed-phase HPLC. Cellular fatty acids were analysed in organisms grown on a trypticase soy agar (TSA; Difco) for 2 days. The cellular fatty acids were saponified, methylated and extracted according to the protocol of the Sherlock Microbial Identification System (MIDI). The fatty acids analysed by a gas chromatograph (Hewlett Packard 6890) were identified by the Microbial ID software package (Sasser, 1990).
Cells of strain TR6- $01^{\mathrm{T}}$ were aerobic, Gram-negative, nonmotile rods. Colonies grown on R2A agar plates (Difco) for 2 days were smooth, circular, non-glossy, yellowish and 2-4 mm in diameter. On R2A agar, TR6- $01^{\mathrm{T}}$ was able to grow at $20-37^{\circ} \mathrm{C}$, but not at 4 or $45^{\circ} \mathrm{C}$. Physiological characteristics of strain TR6- $01^{\mathrm{T}}$ are summarized in the species description and comparisons of selective characteristics with related type strains are shown in Table 1.

The 16S rRNA gene sequence of the strain TR6- $01^{\mathrm{T}}$ was a continuous stretch of $1456 \mathrm{bp}$. Sequence similarity calculations after neighbour-joining analysis indicated that the closest relatives of strain TR6- $01^{\mathrm{T}}$ were $S$. acidaminiphila $(97 \cdot 1 \%)$ and S. maltophilia $(96 \cdot 9 \%)$. Lower sequence similarities $(<97.0 \%)$ were found with all recognized species of the genus Stenotrophomonas.

The DNA G + C content of strain TR6- $01^{\mathrm{T}}$ was $66 \cdot 0 \mathrm{~mol} \%$. Characterization of the respiratory quinone system supports the affiliation of TR6- $01^{\mathrm{T}}$ with the Gammaproteobacteria, where the majority of species in the genus Xanthomonas and Stenotrophomonas have Q-8 as the major quinone (Finkmann et al., 2000). The fatty acid profile of strain TR6$01^{\mathrm{T}}$ (available in Supplementary Table S1 in IJSEM Online) was mainly composed of $\mathrm{C}_{15: 0}$ iso $(34.0 \%), \mathrm{C}_{15: 1}$ iso $\mathrm{F}$ $(18 \cdot 1 \%), \mathrm{C}_{13: 0}$ iso $(8.9 \%), \mathrm{C}_{11: 0}$ iso $(6.8 \%), \mathrm{C}_{11: 0}$ iso 3 $\mathrm{OH}(4 \cdot 8 \%), \mathrm{C}_{14: 0}$ iso $(4 \cdot 2 \%)$, iso $\mathrm{C}_{17: 1} \omega 9 c(3 \cdot 3 \%)$ and $\mathrm{C}_{13: 0}$ iso $3-\mathrm{OH}(3 \cdot 1 \%)$. A significant difference was found compared with other Stenotrophomonas species: the production of a large amount of the fatty acid $\mathrm{C}_{15: 1}$ iso $\mathrm{F}$ $(18 \cdot 1 \%)$. Moreover, S. acidaminiphila produced significantly larger amounts of $\mathrm{C}_{14: 0}$ iso $(17 \cdot 8 \%)$ and $\mathrm{C}_{16: 0}$ iso $(14 \cdot 3 \%)$ and S. rhizophila produced a significantly larger amount of $\mathrm{C}_{15: 0}$ anteiso $(23 \cdot 8 \%)$. Thus, fatty acid profiles can be used to differentiate the members of the genus Stenotrophomonas at the species level.

DNA-DNA hybridization experiments were performed between TR6- $01^{\mathrm{T}}$ and type strains of the genus Stenotrophomonas with the method described by Ezaki et al. (1989) using photobiotin-labelled DNA probes and microdilution wells. DNA-DNA relatedness values of strain TR6- $01^{\mathrm{T}}$ to the other species of genus Stenotrophomonas were $25-42 \%$ ( $40 \%$ to S. acidaminiphila DSM $13117^{\mathrm{T}}, 25 \%$ to S. maltophilia KCTC $1773^{\mathrm{T}}, 42 \%$ to $S$. nitritireducens DSM $12575^{\mathrm{T}}$ and $25 \%$ S. rhizophila DSM $14405^{\mathrm{T}}$ ), which is low enough to assign strain TR6- $01^{\mathrm{T}}$ as a novel species of the genus Stenotrophomonas. On the basis of the data and

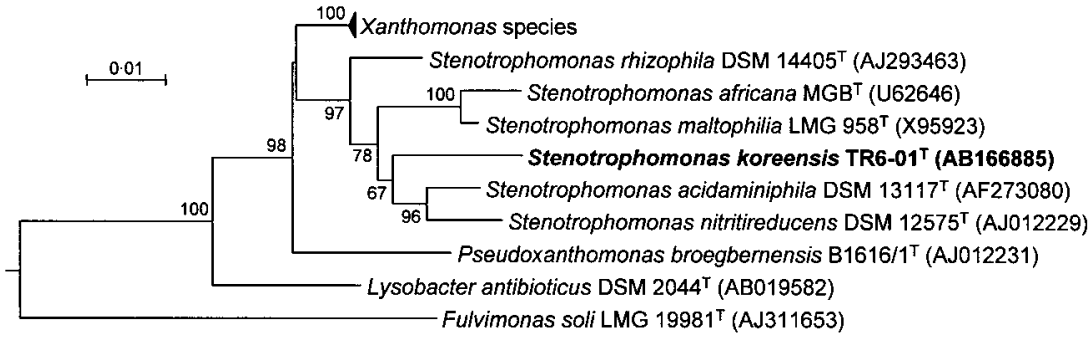

Fig. 1. Phylogenetic tree constructed by the neighbour-joining method from a comparative analysis of $16 \mathrm{~S}$ rRNA gene sequences showing the relationships of $S$. koreensis sp. nov. TR6 $-01^{\top}$ with other related species. Bar, 0.01 substitutions per nucleotide position. Bootstrap values (expressed as percentages of 1000 replications) greater than $65 \%$ are shown at the branch points. 
Table 1. Physiological characteristics of $S$. koreensis TR6- $01^{\top}$ and related type strains of species of genus Stenotrophomonas

Strains: 1, S. koreensis TR6- $01^{\mathrm{T}}$; 2, S. acidaminiphila DSM $13117^{\mathrm{T}}$; 3, S. maltophilia KCTC $1773^{\mathrm{T}}$; 4, S. nitritireducens DSM $12575^{\mathrm{T}}$; 5, S. rhizophila DSM $14405^{\mathrm{T}}$. All analyses were done in this study. + , Positive; -, negative. All strains were positive for utilization of propionate, valerate, L-proline and acetate as carbon sources. All strains were negative for utilization of L-fucose, D-sorbitol, Larabinose, 2-ketogluconate, 4-hydroxybenzoate, D-ribose, inositol, itaconate, 5-ketogluconate, 3-hydroxybenzoate, mannitol, caprate, adipate, phenylacetate and glycogen as carbon sources. All strains were positive for catalase activity and negative for glucose acidification and indole production.

\begin{tabular}{|c|c|c|c|c|c|}
\hline Characteristic & 1 & 2 & 3 & 4 & 5 \\
\hline Nitrate reduction to nitrite & - & + & + & - & + \\
\hline Nitrite reduction & - & + & + & + & - \\
\hline \multicolumn{6}{|l|}{ Enzyme activity: } \\
\hline Oxidase & + & + & - & - & - \\
\hline Arginine dihydrolase & - & - & + & + & - \\
\hline Urease & - & - & + & + & - \\
\hline$\beta$-Glucosidase (aesculin hydrolysis) & - & + & + & - & - \\
\hline Protease (gelatin hydrolysis) & + & - & + & - & + \\
\hline$\beta$-Galactosidase & - & - & + & - & + \\
\hline \multicolumn{6}{|l|}{ Utilization as a sole carbon source: } \\
\hline D-Glucose & - & + & + & + & + \\
\hline Mannose & - & + & + & - & + \\
\hline $\mathrm{N}$-Acetylglucosamine & - & + & + & + & + \\
\hline Maltose & - & + & + & - & + \\
\hline Malate & - & - & + & - & + \\
\hline Citrate & - & - & + & + & + \\
\hline Histidine & - & + & + & + & + \\
\hline Salicin & - & - & - & - & + \\
\hline D-Melibiose & - & - & - & - & + \\
\hline 3-Hydroxybutyrate & + & + & - & + & - \\
\hline Sucrose & - & - & + & - & + \\
\hline Maltose & - & + & + & - & + \\
\hline Suberate & - & - & - & - & + \\
\hline Malonate & - & - & + & - & + \\
\hline DL-Lactate & - & + & + & + & + \\
\hline L-Alanine & + & + & + & + & - \\
\hline L-Serine & + & + & + & + & - \\
\hline
\end{tabular}

observations described above, strain TR6- $01^{\mathrm{T}}$ should be assigned to the genus Stenotrophomonas as the type strain of a novel species, for which the name Stenotrophomonas koreensis sp. nov. is proposed.

\section{Description of Stenotrophomonas koreensis sp. nov.}

Stenotrophomonas koreensis (ko.re.en'sis. N.L. fem. adj. koreensis pertaining to Korea, the location of the compost sample from which the type strain was isolated).
Cells are Gram-negative, strictly aerobic, non-motile, slightly curved rods, $0 \cdot 2-0 \cdot 4 \mu \mathrm{m}$ in diameter and $1 \cdot 5-2 \cdot 0 \mu \mathrm{m}$ in length. Colonies grown on R2A agar (Difco) for 2 days are smooth, circular, non-glossy, yellowish and convex. Grows well at pH $6 \cdot 0-8 \cdot 5$ and at $20-37^{\circ} \mathrm{C}$, but does not grow at 4 or $45{ }^{\circ} \mathrm{C}$. Growth occurs in the presence of $0-2 \cdot 0 \%(\mathrm{w} / \mathrm{v})$ $\mathrm{NaCl}$, but not $4 \%(\mathrm{w} / \mathrm{v}) \mathrm{NaCl}$. It cannot reduce nitrate and nitrite or grow anaerobically. It cannot degrade xylan, chitin, cellulose or starch but can degrade DNA. Substrate utilization, enzyme production, acid production and other physiological characteristics are shown in Table 1. Resistant to discs containing $15 \mu \mathrm{g}$ tetracycline and $15 \mu \mathrm{g}$ streptomycin, but sensitive to $20 \mu \mathrm{g}$ ampicillin and $1.0 \mathrm{mg}$ kanamycin. Q8 is the predominant ubiquinone and $\mathrm{C}_{15: 0}$ iso, $\mathrm{C}_{15: 1}$ iso $\mathrm{F}$, $\mathrm{C}_{13: 0}$ iso and $\mathrm{C}_{11: 0}$ iso are the major cellular fatty acids. The $\mathrm{G}+\mathrm{C}$ content of genomic DNA is $66.0 \mathrm{~mol} \%$ (as determined by HPLC).

The type strain, TR6- $01^{\mathrm{T}}\left(=\mathrm{KCTC} 12211^{\mathrm{T}}=\mathrm{JCM} 13256^{\mathrm{T}}\right)$, was isolated from a compost consisting of cow dung and rice straw, near Daejeon City, Korea.

\section{Acknowledgements}

This work was supported by the 2005 Research Program of the Rural Development Administration, Republic of Korea.

\section{References}

Assih, E. A., Ouattara, A. S., Thierry, S., Cayol, J. L., Labat, M. \& Macarie, H. (2002). Stenotrophomonas acidaminiphila sp. nov., a strictly aerobic bacterium isolated from an upflow anaerobic sludge blanket (UASB) reactor. Int J Syst Evol Microbiol 52, 559-568.

Atlas, R. M. (1993). Handbook of Microbiological Media. Edited by L. C. Parks. Boca Raton, FL: CRC Press.

Buck, J. D. (1982). Nonstaining (KOH) method for determination of Gram reactions of marine bacteria. Appl Environ Microbiol 44, 992-993.

Cappuccino, J. G. \& Sherman, N. (editors) (2002). Microbiology: a Laboratory Manual, 6th edn. San Francisco: Benjamin Cummings.

Drancourt, M., Bollet, C. \& Raoult, D. (1997). Stenotrophomonas africana sp. nov., an opportunistic human pathogen in Africa. Int J Syst Bacteriol 47, 160-163.

Ezaki, T., Hashimoto, Y. \& Yabuuchi, E. (1989). Fluorometric deoxyribonucleic acid-deoxyribonucleic acid hybridization in microdilution wells as an alternative to membrane filter hybridization in which radioisotopes are used to determine genetic relatedness among bacterial strains. Int J Syst Bacteriol 39, 224-229.

Felsenstein, J. (1985). Confidence limit on phylogenies: an approach using the bootstrap. Evolution 39, 783-791.

Finkmann, W., Altendorf, K., Stackebrandt, E. \& Lipski, A. (2000). Characterization of $\mathrm{N}_{2} \mathrm{O}$-producing Xanthomonas-like isolates from biofilters as Stenotrophomonas nitritireducens sp. nov., Luteimonas mephitis gen. nov., sp. nov. and Pseudoxanthomonas broegbernensis gen. nov., sp. nov. Int J Syst Evol Microbiol 50, 273-282.

Hall, T. A. (1999). BIOEDIT: a user-friendly biological sequence alignment editor and analysis program for Windows 95/98/NT. Nucleic Acids Symp Ser 41, 95-98. 
Im, W.-T., Kang, M.-S., Park, H.-Y., Kim, M.-K. \& Lee, S.-T. (2003). Culturable bacterial strain's diversity of environmental samples. In Proceedings of the International Meeting of the Federation of Korean Microbiological Societies, abstract B4023, p. 165. Seoul: Federation of Korean Microbiological Societies.

Im, W.-T., Bae, H.-S., Yokota, A. \& Lee, S. T. (2004). Herbaspirillum chlorophenolicum sp. nov., a 4-chlorophenol-degrading bacterium. Int J Syst Evol Microbiol 54, 851-855.

Kimura, M. (1983). The Neutral Theory of Molecular Evolution. Cambridge: Cambridge University Press.

Komagata, K. \& Suzuki, K. (1987). Lipids and cell-wall analysis in bacterial systematics. Methods Microbiol 19, 161-203.

Kouker, G. \& Jaeger, K.-E. (1987). Specific and sensitive plate assay for bacterial lipase. Appl Environ Microbiol 53, 211-213.

Kumar, S., Tamura, K., Jacobsen, I.-B. \& Nei, M. (2001). MEGA2: molecular evolutionary genetics analysis software. Bioinformatics 17, 1244-1245.

Mesbah, M., Premachandran, U. \& Whitman, W. B. (1989). Precise measurement of the $\mathrm{G}+\mathrm{C}$ content of deoxyribonucleic acid by highperformance liquid chromatography. Int J Syst Bacteriol 39, 159-167.
Palleroni, N. J. \& Bradbury, J. F. (1993). Stenotrophomonas, a new bacterial genus for Xanthomonas maltophilia (Hugh 1980) Swings et al. 1983. Int J Syst Bacteriol 43, 606-609.

Saitou, N. \& Nei, M. (1987). The neighbor-joining method: a new method for reconstructing phylogenetic trees. Mol Biol Evol 4, 406-425.

Sasser, M. (1990). Identification of bacteria by gas chromatography of cellular fatty acids. MIDI Technical Note 101. Newark, DE: MIDI Inc.

Ten, L. N., Im, W.-T., Kim, M.-K., Kang, M.-S. \& Lee, S.-T. (2004). Development of a plate technique for screening of polysaccharidedegrading microorganisms by using a mixture of insoluble chromogenic substrates. J Microbiol Methods 56, 375-382.

Thompson, J. D., Gibson, T. J., Plewniak, F., Jeanmougin, F. \& Higgins, D. G. (1997). The CLUSTAL_X windows interface: flexible strategies for multiple sequence alignment aided by quality analysis tools. Nucleic Acids Res 25, 4876-4882.

Wolf, A., Fritze, A., Hagemann, M. \& Berg, G. (2002). Stenotrophomonas rhizophila sp. nov., a novel plant-associated bacterium with antifungal properties. Int J Syst Evol Microbiol 52, 1937-1944. 